different herds is shown in Figure 1 with the confidence interval of the mean. The FEC of the non resistant herd grazing with heifers (M0) is significantly higher than the FEC of the 2 resistant herds $(M+$ and $R+)$. The effect of selection improves the ability of the does to control parasite infection. The effect of the grazing mode was not significant enough to explain the difference between the herds for the FEC.

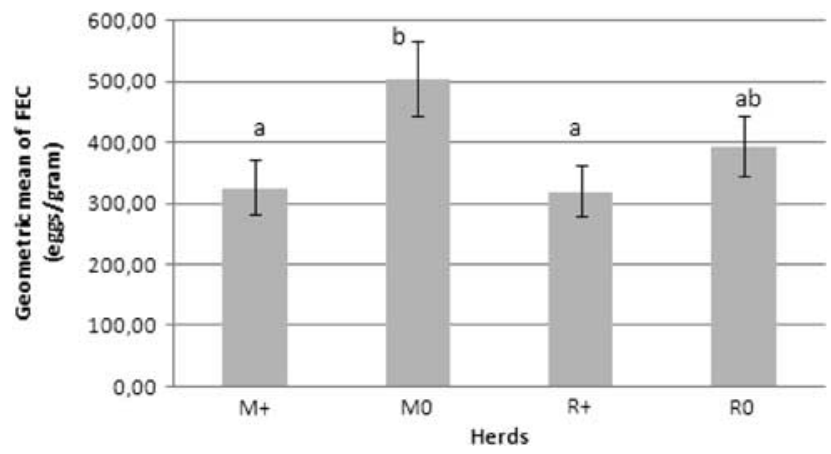

Figure 1 Evolution of the geometric mean of FEC (eggs/gram) (mean of FEC at weeks 4 and 6 after kidding) Columns topped by different letters differ significantly $(P<0.05)$.

\title{
Conclusion and perspectives
}

These first results suggest a better resistance to GIN of the resistant-selected herds $(M+$ and $\mathrm{R}+$ ) compared to the non resistant herd grazing with heifers (M0). However, doe infection is one aspect of the comparison. The performance of the herds will also be studied using other parameters like PCV and EOSI to assess the parasite infection characteristics. The kid average daily gain (ADG) will allow estimating the milk output of the does (ADG 10 to 30 day) and the kid growth potential (ADG 30 to 70 day). The estimates of the litter weight at weaning and of the doe and cattle weight variations will allow comparing the productivity of the four herds.

\section{Aknowledgments}

The authors thanks the European Community (FEOGA) and "La Région Guadeloupe" for their financial support.

H. Varo and L. Abinne-Molza from parasitological laboratory and the small ruminant team in Gardel for their technical assistance are also warmly thanked.

\section{References}

Mahieu M, Aumont G, Michaux Y, Alexandre G, Archimède H and Boval M 1997. INRA Productions Animales 10 (1), 55-65.

Mandonnet N, Bachand M, Mahieu M, Arquet R, Baudron F and Abinne-Molza L 2005. Veterinary Parasitology 134, $249-259$.

Mandonnet N, Menendez-Buxadera A, Arquet R, Mahieu M, Bachand M and Aumont G 2006. Animal Science 82, $283-287$.

doi:10.1017/S2040470010000415

\section{Morphological characterization and breeding system identification of local sheep breeds in Niger}

\author{
Bello Abina Abdoul Karim ${ }^{1 \dagger}$, Pr. Djemali M'Naouer ${ }^{1}$ and Dr Augustine Ayantundé2 \\ ${ }^{1}$ Institut National Agronomique de Tunis (INAT) avenue Charles Nicoles 1002 Tunis-Tunisie; ${ }^{2}$ International Livestock Researche Institut (ILRI-Niger)/ICRISAT-Niger
}

In Niger, livestock breeding is the second rural population activity, contributing $12 \%$ to the national GDP and $40 \%$ to agricultural production. The national livestock include a large range of domestic animal species among which ovine species, which represent $20 \%$ of this livestock. These ovine resources constitute an important genetic variety source, well adapted to the rough environmental conditions of Niger. However, these genetic resources are generally very little known and subjected to inappropriate breeding practices by their holders (shepherds and farmers). These factors contribute to reducing their productive and reproductive potential and threaten the integrity of some native breeds.

\footnotetext{
†E-mail: baak_ne@yahoo.fr
} 
In order to prevent these risks, it is indispensable to learn more on the breeds and dread farmer's motivation for anarchic breeding practices. This study was aimed at prospecting farmers' management followed by an inventory and morphological characterization of these ovine resources in their own ecosystem. Investigation data were analyzed by SAS software (SAS Vs9).

Ninety breeders were surveyed among which $91 \%$ stemming from the rural population show three main types of traditional systems exploiting ovine resources according to their food behavior and breeding environment: the extensive system ( $30 \%$ of the breeders) where supply is essentially based on natural pastures; the semi-extensive system (65\% of the breeders), which associates breeding and where the agriculture is expanding in the sahel; the Urban and Outer-urban system ( $5 \%$ of the breeders) in which the main part of animals supply comes from household residues and some bought feed. Moreover, in these systems, cross-breeding is common, thus, about $51 \%$ of the investigated breeders have crossed subjects voluntarily or not in their herds.

The characterization investigations were carried out on 324 Niger sheep; the breed phenotypic characterization for their production field, spread over 4 ethnic regions (Fakara, Sinder, Manga and Zarmaganda) and concerned 5 Niger native sheep breeds among which three meat breeds: the Oudah with two-colored fleece and Bali Bali with fleece are both of big size and raised by Fulani communities in southwest areas; the Tuareg Ara Ara breed is high on leg with average size being used in the north pastoral regions; two wool breads - the Koudoum found on the banks and Kourtèye islands of Niger River and the Toubou or Hadine breeds in Manga (in the southeast); Besides these breads, there are two breeds introduced for strong butcher capacities - the Balami (native of Nigeria) introduced constantly by shepherds into border areas of Nigeria and the Sudanese (native of Sudan) introduced recently into Manga areas via the Chadian border.

\title{
Meat quality potential of Creole goats fed two contrasted diets: fatty acid composition of fat and muscle tissues
}

\author{
Gisèle Alexandre ${ }^{\dagger}$, L. Liméa, Harry Archimede and Nathalie Mandonnet \\ INRA, UR143Unité de Recherches Zootechniques, F-97170 Petit Bourg, France
}

\begin{abstract}
Introduction
In the Caribbean region, goat farming is centered on the Creole breed which is a hardy genotype' reared for meat, known for its good adaptative and reproductive traits (Alexandre and Mandonnet, 2005). Published information on the meat potential ability of this breed is scant and there is lack of factual data on intensive feedlot systems. Increasing kid performances using high concentrate diets may result in fat carcasses (Webb et al., 2005; Ryan et al., 2007). The objective of this study was to assess the effects of diet upon the fatty acid (FA) composition of the fat and muscle tissues.
\end{abstract}

\section{Materials and methods}

After weaning (9.2 kg LW), 91 kids were reared in collective pens on a slatted floor and allocated by weight and preweaning growth and randomly assigned to 2 experimental groups. In group C0 $(n=45)$ kids were offered basal tropical forage diet while in group C50 ( $n=46)$ they were also offered concentrate $(50 \%$ of the diet). Animals were sacrificed according to standardized procedure. After removal of the left shoulder on the cold carcass, supraspinus muscle (SE) and intramuscular (IM) fat were dissected for chemical determination. The FA extraction was carried out as described by Bas et al. (2005). The FA were added up according to family: SFA = Saturated FA; MUFA = Monounsatured FA and PUFA = Polyunsatured FA. Data were analysed using PROC GLM (SAS, Inc) with diet as the main effect in the model and carcass weight as covariable ( kept in the model when significant).

\section{Results and discussions}

The diet greatly influenced the meat quality, mainly due to the addition of concentrate and as reported elsewhere (Webb et al., 2005). In regards to SFA health aspects, goat meat composed of IM and muscle tissues was not different (Table $1 \mathrm{a}, 1 \mathrm{~b}$,). The results are controversial in the literature as reviewed by Webb et al. (2005). Creole goats contained higher MUFA and PUFA in SE muscle, which are considered as desirable FA (Pratiwi et al., 2006). The total odd FA ranged from 2.3 to $4.4 \%$ of the total FA in all tissues, and the results are in the lower range of what is usually observed except for the CO kids whose results agreed with those of Bas et al. (2005) on kids under Moroccan conditions. The proportions of FA from the $n-3$ series were classically higher in the muscle than in the fat tissues. Values were in the range observed in goats fed argan pulp (Bas et al., 2005), but lower than those fed browse-diet (Ryan et al., 2007). A greater enrichment in n-3FA in kids fed forage resulted to a better ratio of n-6/n-3 FA composition (Pratiwi et al., 2006; Ryan et al., 2007).

\footnotetext{
† E-mail: gisele.alexandre@antilles.inra.fr
} 